OPEN ACCESS

Edited by:

Catherine Woodstock Striley, University of Florida, United States

Reviewed by:

Rodrigo Marín-Navarrete, Instituto Nacional de Psiquiatría Ramón de la Fuente Muñiz (INPRFM),

Mexico

Aya Kinjo,

Tottori University, Japan

${ }^{*}$ Correspondence:

Marc N. Potenza

marc.potenza@yale.edu

Specialty section: This article was submitted to

Addictive Disorders, a section of the journa

Frontiers in Psychiatry

Received: 08 April 2019 Accepted: 21 May 2019 Published: 14 June 2019

Citation:

Vaccaro $A G$ and Potenza MN (2019) Diagnostic and Classification

Considerations Regarding

Gaming Disorder: Neurocognitive and Neurobiological Features.

Front. Psychiatry 10:405. doi: 10.3389/fpsyt.2019.00405

\section{Diagnostic and Classification Considerations Regarding Gaming Disorder: Neurocognitive and Neurobiological Features}

\author{
Anthony G. Vaccaro ${ }^{1,2}$ and Marc N. Potenza ${ }^{1,3,4,5,6 *}$ \\ ${ }^{1}$ Child Study Center, Yale University School of Medicine, New Haven, CT, United States, ${ }^{2}$ Brain and Creativity Institute, \\ Dornsife College of Arts and Sciences, University of Southern California, Los Angeles, CA, United States, ${ }^{3}$ Department of \\ Psychiatry, Yale University School of Medicine, New Haven, CT, United States ${ }^{4}$ Department of Neuroscience, Yale University \\ School of Medicine, New Haven, CT, United States, ${ }^{5}$ Connecticut Council on Problem Gambling, Wethersfield, CT, United \\ States, ${ }^{6}$ Connecticut Mental Health Center, New Haven, CT, United States
}

Video gaming and Internet use have become a part of the everyday lives of many individuals, especially during adolescence. Given the health concerns related to problematic gaming behaviors, gaming disorder (GD) has been included in the version of the 11th edition of The International Classification of Diseases (ICD-11) ratified by the secretariat of the World Health Organization. Given these considerations and others (including debate regarding the most appropriate classification of GD and how best to prevent and treat the condition), there is a need for further research into GD. Specifically, we suggest that researching intermediate phenotypes focusing on cognitive and neurobiological function may help clarify GD's relationships to other addictive disorders and more accurately define their relationships with core and associated features of GD. Overlaps in neural activity, cognitive functioning, and other features suggest that GD shares similarities with gambling and substance-use disorders and may best be classified as an addictive disorder. Individuals with GD differ from those with regular game use (RGU) on neurocognitive levels. However, concerns have been raised with respect to the differences between GD and substance-use disorders in certain dimensional features, such as tolerance. Additionally, it has been argued that differences between GD and RGU may not be fully captured by nomenclature systems like the ICD-11. Nonetheless, individuals seek treatment for help with GD, despite the limited data available for effective treatments. As more data are gathered from investigations of GD, they should be translated into refining criteria for GD and optimizing interventions.

Keywords: gaming disorder, internet gaming, recreational gaming, behavioral addiction, DSM-5, ICD-11

\section{HOW BEST TO DEFINE GAMING DISORDER, ESTIMATE ITS PREVALENCE AND CONSIDER RELATIONSHIPS WITH INTERMEDIATE PHENOTYPES?}

As the world has become increasingly "digitalized," the prevalence of video gaming has increased substantially. As of 2016, the video game market was a 99.6 billion dollar industry and was 
estimated to reach 118 billion by 2019 (1). As of 2012, an estimated 1 billion people played computer games, and based on economic trends, it is likely that this number has since risen (2). Gaming is especially prevalent among children and adolescents, with an estimated $68 \%$ of 8 - to 18 -year-olds in the United States playing at least weekly (3). Like some other facets of technologies and their usage, gaming has, at times, come under scrutiny because of proposed links to increased violent behaviors in children, possible negative impacts on intellectual development, and lack of constructiveness. Links to aggression have been reported by some investigators to be absent or less strong than some have proposed (4), and while gaming has been reported to be linked to increased cognitive abilities in visuospatial and attention domains in some studies (5), a recent meta-analysis questions these findings (6). While most individuals game without significant concerns, there is growing evidence that some individuals may develop problematic gaming behaviors, possibly of an addictive nature. In this article, we will consider how problematic gaming has been defined in major nomenclatures systems, how different definitions have led to variations in prevalence estimates, and how investigating neurocognitive factors as potential intermediate phenotypes may help promote a better understanding of the clinical neurobiology of problematic gaming or gaming disorder (GD).

The prevalence of "addictive gaming behaviors" may vary across cultures, with estimates as low as $1.16 \%$ of adolescents in Germany, to as high as $5.9 \%$ in South Korea $(7,8)$, with wider prevalence estimates also noted in earlier studies (9). Estimates have varied greatly, depending on thresholds for "cases," with estimates in adolescents, for example, ranging from $0.3 \%$ in Germany to $50 \%$ in South Korea (2). Furthermore, some studies have grouped different forms of addictive patterns of Internet use together, leading to larger estimates, such as $2.1 \%$ in Germany and $12.4 \%$ in South Korea $(10,11)$. As such, evaluating the prevalence of gaming problems while considering potential cultural/jurisdictional differences as well as potential differences relating to the instruments assessing gaming problems is important $(12,13)$.

The large range of estimates on the prevalence of problematic gaming in part relates to varying definitions. Across studies, names include "Gaming Disorder" (GD), "Gaming Addiction," "Internet Gaming Addiction," and "Internet Gaming Disorder" (IGD). Although the names may vary, gaming is a core behavior, and problems are a core feature. Furthermore, the terms "Internet Addiction Disorder" and related constructs may also include GD. For instance, while South Korea has officially used the term Internet addiction disorder (IAD), online gaming comprises $67 \%$ of middle school boys' recreational use of the Internet, the group with the highest prevalence of IAD (11). The Diagnostic and Statistical Manual of Mental Disorders, 5th edition (DSM-5), published in 2013 and researched and worked on for approximately a decade prior, suggests that evidence for IGD, in part derived from existing data at the time on IAD in young males from Asian countries, may not generalize to non-gaming Internet use (14). Across researchers, the views on this potential disorder range from GD being officially recognized as an official disorder to being seen as a pathologizing of normal behavior that may generate moral panic $(2,11,15,16)$. Another debate involves whether gaming behavior should be considered addictive, with some contending that excessive gaming may include continued engagement despite adverse consequences that may involve ineffective time management, gaming to escape from negative mood states or stress, or addictive features of games (17). Like with gambling disorder, IGD may share core components of addiction, including continued engagement despite adverse consequences, impaired control or compulsive engagement, and an appetitive urge or craving that may precede behavioral engagement (18). In the DSM-5, IGD is included under "Conditions for Further Study," suggesting that in individuals with IGD, gaming may activate similar reward-related pathways as drugs do in individuals with drug addictions (14). Such data, along with findings related to withdrawal and significant social and cognitive impairment linked to excessive gaming, mirror those of substance-use disorders; however, differences have also been noted. Some criteria included in the DSM-5 for IGD, such as tolerance, may not be as central to IGD as to substance-use disorders. Individuals with IGD may be particularly motivated by complex and specific in-game goals, and by a fear of missing out in multiplayer games; this may be different from aspects of tolerance in substance-use disorders (19). Potential differences between IGD and substance-use disorders may be found for other criteria as more research is conducted.

With the generation of the The International Classification of Diseases, 11th edition (ICD-11), GD was included as a disorder due to addictive behaviors, with some researchers arguing against the inclusion (20) and others citing the relevance to personal and public health (21). Some of the debate focuses on whether there is sufficient evidence for GD to be included in ICD-11, citing the possibility of pathologizing normal behavior. However, others report that having a defined disorder should not interfere with most individuals who engage in gaming and would importantly promote generating a framework for helping those who might be experiencing harms related to gaming. Further, the inclusion of a hazardous gaming entity, like that has been used for other addictive behaviors like alcohol consumption, has been debated but may be particularly important from public health perspectives (22). These debates regarding GD share features with others in psychiatry historically (e.g., with respect to substance-use disorders) with respect to how best to define and classify disorders (23). With current categorical systems like those in the ICD-11 and DSM-5, concerns have been raised that defined entities described as discrete in reality are not distinct from others (24). This consideration may be especially concerning when behaviors exist on a spectrum from common normalcy to harmful, as is gaming.

Alternative and non-mutually exclusive dimensional approaches like the research domain criteria (RDoC) or others that focus on intermediate phenotypes may be important to consider as alternate or complementary ways of considering such behaviors or processes. Some intermediate phenotypes focus on cognitive processes or tendencies linked to brain structure and function. As such, we will now consider the neurocognitive evidence for IGD not only as it relates to substance-use disorders, but also as it relates to recreational gaming. 


\section{NEUROCHEMICAL AND FUNCTIONAL NEURAL CIRCUITRIES IN INTERNET ADDICTION AND GAMING DISORDER}

Dopaminergic systems have been proposed to contribute to reward processing in IGD, and in addictions more broadly (25), although the centrality of dopamine to behavioral $(26,27)$ and substance (28) addictions has been questioned. Individuals with Internet addiction, compared with those without, have been reported to have lower dopamine D2-like receptor availability in the striatum and to have lower levels of striatal dopamine transporter expression $(29,30)$. Dopamine D2-like receptor availability in the striatum has also been inversely related to severity of Internet addiction and decreased glucose metabolism in the orbitofrontal cortex (31). All three studies included five individuals with Internet addiction so findings should be considered highly preliminary. In a possible link to genetic vulnerability, the Taq1A1 allele of $D R D 2$, a gene coding for the dopamine D2 receptor, has been reported to be more prevalent in individuals with excessive/problematic gaming and associated with greater reward dependence (32) As DRD2 is in linkage disequilibrium with ankk1 and allelic variation in the coding region of ankk1 has been more closely linked to addictions (e.g., alcohol-use disorders) than those in DRD2 per se $(33,34)$, questions exist as to the extent to which the observed findings may link to dopamine. Bupropion, a norepinephrine-dopamine reuptake inhibitor, may reduce cravings and cue-induced activation of the dorsolateral prefrontal cortex (DLPFC) in individuals with IGD (35). Higher scores on Internet addiction scales have been found to be associated with reduced $\mathrm{N}$-acetyl aspartate in the right frontal cortex in young individuals with Internet gaming addiction (36).

Functional imaging studies have implicated cortical and striatal brain regions in IGD, particularly in males. Gaming cueinduced activity in the striatum (ventral and dorsal) has been reported to be greater in individuals with IGD as compared with those without, although activation in the left ventral striatum was negatively correlated with intensities of cue-induced cravings (37). Responses to gaming cues may change following forced immediate abstinence, and findings suggest that changes in DLPFC activation during forced immediate abstinence may in part underlie male vulnerability to IGD (38). Further, changes in functional connectivity between regions implicated in reward processing (e.g., striatum) and cognitive control (e.g., DLPFC) prior to gaming and during forced immediate abstinence may explain the progression of IGD in a gender-sensitive fashion (39). Resting-state functional connectivity between the ventral tegmental area and the nucleus accumbens, a region in the ventral striatum, has also been reported to negatively correlate with craving intensities, and with less strength in connectivity between these regions noted in individuals with IGD as compared to those without (40). The insula has been implicated in IGD with relatively decreased resting-state functional connectivity observed between regions of the insula and those like the supplementary motor areas, cingulate cortex, and superior frontal gyrus, suggesting diminished resting communication between regions implicated in interoceptive processing, craving, and other processes and the ones involved in motoric behaviors and cognitive and behavioral control (41). The processing of gaming cues and resting-state connectivity may also relate to treatments for IGD. For example, increased insula activity to gaming cues has been observed following a craving behavioral intervention in IGD, with relatively diminished connectivity between the insula (implicated in cue reactivity and interoceptive processing) and regions implicated in drug craving like the precuneus are also seen (42). Following a craving-behavioral intervention, resting-state functional connectivity was decreased between the orbitofrontal cortex and hippocampus and between the posterior cingulate and supplemental motor area (43). These findings link changes in connectivity between regions implicated in craving to those involved in memory and motoric planning processes, respectively, suggesting possible neurobiological mechanisms for a craving behavioral treatment for IGD.

Functional MRI studies may investigate neural correlates of cognitive processes including those related to control and reward/loss processing, as hypothesized to be important in IGD and other Internet-use disorders $(44,45)$. Individuals with IGD, as compared with those without, have demonstrated less functional connectivity within executive control regions, and this has been linked to behavioral measures of cognitive control (46). Individuals with IGD show greater frontal cortical activation during a cognitive control task than those with regular- or lowfrequency game use (43). On a guessing task, an IGD group demonstrated relatively weaker frontal cortical activations during processing of losses and relatively weaker activation of cortico-striatal regions during processing of wins (47). During a risk-related decision-making task, in IGD participants there was relatively weaker modulation for experienced risk in cortical regions (DLPFC and inferior parietal areas) and increased activation of striatal and ventromedial and orbitofrontal cortices during rewarding outcomes (48). Relationships with IGD severity were noted in both studies. A separate study found that IGD subjects showed relatively decreased involvement of the inferior frontal and precentral gyri when making probabilistic choices (49). Differences in the processing of emotional cues have also been noted in IGD, with relatively blunted activation of corticostriatal regions noted in response to negative affective cues and during emotional regulation in the striatum, insula, lateral prefrontal cortex, and anterior cingulate (50). A meta-analytic review indicated that individuals with IGD as compared with those without demonstrated relatively increased activity in the anterior and posterior cingulate cortices, caudate, and posterior inferior frontal gyrus during reward and "cold" executive functions, relatively decreased activity in the anterior inferior frontal gyrus in relation to "hot" executive functions, and relatively decreased activity in the posterior insula, somatomotor, and somatosensory cortices during reward processing (51). Together, these findings suggest neural mechanisms for disadvantageous decisionmaking, impaired control, and dysregulated reward processing in IGD.

The neurochemical and genetic studies of IGD highlight shared features with other addictive disorders. These shared 
elements suggest that IGD has similar biological underpinnings with more established addictive disorders.

\section{NEUROCOGNITION OF INTERNET GAMING DISORDER COMPARED WITH OTHER ADDICTIONS}

Although relatively few studies have directly compared and contrasted neural correlates in IGD with those of substanceuse disorders as has been done for gambling disorder [e.g., see Refs. $(52,54)]$, similarities have been noted between the neural correlates of IGD and substance-use disorders. Individuals with IGD have been reported to exhibit similarly decreased neural activity in response to losses, and increased sensitivity to cues, as in gambling and substance-use disorders (55). Responses to tobacco and gaming cues may include activations in the anterior cingulate and parahippocampus with tobacco-use disorder and IGD (56). IGD and alcohol-use disorder have been reported to share increased resting state regional homogeneity in the posterior cingulate cortex, with the IGD group showing decreased resting state regional homogeneity in the superior temporal gyrus compared with alcohol-use disorder and non-affected groups (57). While both IGD and alcohol-use disorder groups have demonstrated positive resting state functional connectivity between the DLPFC, cingulate, and cerebellum, the IGD group showed negative resting state functional connectivity between the DLPFC, temporal lobe, and striatal areas and the alcoholuse disorder groups showed positive resting-state functional connectivity between these regions (58).

The extent to which similarities may reflect common brain mechanisms across conditions may link to specific intermediate phenotypes [e.g., impulsivity, as has been implicated in brain studies across behavioral drug addictions (59)] and differences may relate to unique features of the conditions (e.g., substance effects on brain substrates) warrants additional investigation.

\section{PROBLEMATIC VERSUS REGULAR GAMING}

Recent studies have begun to include groups whose members game frequently for recreation, but do not experience negative consequences (a behavioral pattern termed "regular game use" or RGU). The use of an RGU group that reports similar amounts of time gaming as the IGD group but without the negative consequences removes a potential confound related to gaming experience that may be levied against studies of IGD and nongaming groups. Some of the findings comparing groups with IGD and those with RGU are similar to those observed in individuals with substance-use disorders. As mentioned above, individuals with IGD as compared with those with RGU demonstrated poorer cognitive control that was associated with greater frontal activation and weaker activations of frontal and cortico-striatal regions during processing of losses and wins (47). Individuals with IGD as compared with those with RGU have been reported to exhibit less cortical thickness in the orbitofrontal cortex, inferior parietal lobule, cuneus, precentral gyrus, and right middle temporal gyrus (60). Cortico-striatal pathways also differentiate those with IGD from those with RGU with respect to craving, with IGD subjects showing greater striatal-thalamic connectivity and decreased DLPFC-superior frontal gyrus connectivity during immediate forced abstinence, with both patterns of connectivity correlating with craving intensity (39). Individuals with RGU who subsequently develop IGD have been reported to exhibit increased lentiform activation to gaming cues following gaming (61). Further, findings suggesting better white matter integrity in individuals with IGD as compared with those with RGU were reported, implicating tracts involved in processing rewards and generating sensory and motor control and linking to measures of addiction severity (62). Individuals with IGD as compared to those who are professional gamers decreased gray matter volume in cingulate gyrus and increased thalamus gray matter volume, with additional differences noted between groups, including relatively decreased volumes in the IGD and professional gaming groups relative to a non-gaming control group (63). Of note, the IGD group was more impulsive and showed more perseverative errors relative to the non-gaming group, consistent with the notion that aspects of impaired control and compulsivity may be more relevant to IGD than to other gaming and non-gaming groups $(45,64)$.

Beyond time spent gaming, functional impairment is an important consideration in IGD. Intermediary phenotypes, such as impulsivity and urge or craving states, are important in IGD as in other more well researched addictive disorders. These cognitive factors relate to gray and white matter measures in subjects with IGD, and more research is needed to determine whether these findings may predispose or be a consequence of problematic gaming.

\section{FUTURE DIRECTIONS}

IGD in the DSM-5 and GD in the ICD-11 are likely heterogeneous entities, and an improved understanding of relevant individual differences will likely help diagnostic, classification, prevention, and treatment efforts. Additional direct examination of IGD as compared to other addictive disorders is warranted. Examinations targeting a broader range of neurobiological systems implicated in behavioral and drug addictions, such as glutamatergic, serotonergic, noradrenergic, GABAergic, and stress hormonal systems (65), should be conducted in IGD. Intermediate phenotypes, including impulsivity, compulsivity, positive and negative valence systems measures, social cooperation, stress responsiveness, emotional processing, and others, warrant further investigation regarding their relevance to IGD (66-69), especially as some of these features have been linked to mental health in IGD (70). Other features like escapism and gamingspecific aspects (e.g., use of avatars, discrepancies between ideal/ virtual and actual self) also warrant consideration (71-73). Such research should also be extended to a broader range of Internetuse disorders (74), especially as gaming appears linked to other Internet-use behaviors like pornography viewing (75), and support for such research will be important (76). Types of gaming 
(including online and offline, as well as types/genres) should also be considered $(77,78)$, particularly as the genres of games people play the most may relate importantly to treatment outcomes (78).

Identifying individuals with IGD will be important, and the implementation of culturally sensitive and validated screening instruments will assist in this process (79). This process should be extended to additional jurisdictions and strive for briefer instruments, and such efforts are currently underway in conjunction with the World Health Organization. This will be particularly important as most people with gambling disorder do not receive treatment (80), and this is likely the case with IGD as well (81). Further research into effective treatments (especially placebo-controlled, randomized clinical trials) is needed, especially since many individuals seeking treatment for IGD continue to experience difficulties at 1- to 5-year follow-ups (82). While some data support the efficacy of specific interventions (for example, a craving behavioral intervention incorporating elements of mindfulness and cognitive behavioral therapy), randomized clinical trials are needed $(42,43)$. Considering the applicability of behavioral and pharmacological approaches effective in the treatments of addictions or other disorders that frequently co-occur with IGD (e.g., depression, attentiondeficit hyperactivity disorder) may facilitate and accelerate this process, as has been proposed for gambling disorder in which co-occurring disorders have been reported to be helpful in selecting appropriate pharmacotherapies in the absence of

\section{REFERENCES}

1. The association for UK Interactive Entertainment: global gaming fact sheet. from https://ukie.org.uk

2. Kuss DJ. Internet gaming addiction: current perspectives. Psychol Res Behav Manag (2013) 6:125-37. doi: 10.2147/PRBM.S39476

3. Gentile D. Pathological video-game use among youth ages 8 to 18: a national study. Psychol Sci (2009) 20(5):594-602. doi: 10.1111/j.1467-9280.2009.02340.x

4. Ferguson CJ. The good, the bad and the ugly: a meta-analytic review of positive and negative effects of violent video games. Psychiatr Q (2007) 78(4):309-16. doi: 10.1007/s11126-007-9056-9

5. Green CS, Bavelier D. Learning, attentional control, and action video games. Curr Biol (2012) 22(6):R197-R206. doi: 10.1016/j.cub.2012.02.012

6. Sala G, Tatlidil KS, Gobet F. Video game training does not enhance cognitive ability: a comprehensive meta-analytic investigation. Psychol Bull (2018) 144:111-39. doi: 10.1037/bul0000139

7. Rehbein F, Psych G, Kleimann M, Mediasci G, Mößle T. Prevalence and risk factors of video game dependency in adolescence: results of a German nationwide survey. Cyberpsychol Behav Soc Netw (2010) 13(3):269-77. doi: 10.1089/cyber.2009.0227

8. Yu H, Cho J. Prevalence of Internet gaming disorder among Korean adolescents and associations with non-psychotic psychological symptoms, and physical aggression. Am J Health Behav (2016) 40(6):705-16. doi: 10.5993/AJHB.40.6.3

9. Petry NM, O'Brien CP. Internet gaming disorder and the DSM-5. Addiction (2013) 108:1186-7. doi: 10.1111/add.12162

10. Müller KW, Glaesmer H, Brähler E, Woelfling K, Beutel ME. Prevalence of Internet addiction in the general population: results from a German population-based survey. Behav Inf Technol (2014) 33(7):757-66. doi: 10.1080/0144929X.2013.810778

11. Heo J, Oh J, Subramanian SV, Kim Y, Kawachi I. Addictive Internet use among Korean adolescents: a national survey. PLoS One (2014) 9(2):e87819. doi: 10.1371/journal.pone.0087819 medications with specific indications for gambling disorder (83). Considering potential developmental impacts of gaming and GD is also important (84). The inclusion of GD in the ICD-11 should help ensure that there is recognition of gaming-related in a subgroup of individuals in a manner that does not pathologize RGU (85), especially if functional impairment is taken into consideration (86), and the inclusion should help promote prevention, treatment, and public health efforts (21).

\section{AUTHOR CONTRIBUTIONS}

AV wrote the first draft in consultation with MP, and MP edited and revised the drafts. Both authors agree to the final submitted version.

\section{FUNDING}

MP has received support from the Connecticut State Department of Mental Health and Addiction Services, the Connecticut Mental Health Center, the Connecticut Council on Problem Gambling, and the National Center for Responsible Gaming. The funding agencies did not provide input or comment on the content of the article, and the content of the article reflects the contributions and thoughts of the authors and do not necessarily reflect the views of the funding agencies.

12. Przybylski AK, Weinstein N, Murayama K. Internet gaming disorder: investigating the clinical relevance of a new phenomenon. Am J Psychiatry (2017) 174:230-6. doi: 10.1176/appi.ajp.2016.16020224

13. Yao YW, Potenza MN, Zhang JT. Internet gaming disorder within the DSM-5 framework and with an eye toward ICD-11. Am J Psychiatry (2017) 174(5):486-7. doi: 10.1176/appi.ajp.2017.16121346

14. American Psychiatric Association. Diagnostic and statistical manual of mental disorders fifth edition DSM-5TM. Arlington: American Psychiatric Association (2013). doi: 10.1176/appi.books.9780890425596

15. Saunders JB, Hao W, Long J, King D, Mann K, Fauth-Bühler M, et al. Gaming disorder: its delineation as an important condition for diagnosis, management and prevention. J Behav Addict (2017) 6(3):271-9. doi: 10.1556/2006.6.2017.039

16. Aarseth E, Bean AM, Boonen H, Colder Carras M, Coulson M, Das D, et al. Scholars' open debate paper on the World Health Organization ICD11 gaming disorder proposal. J Behav Addict (2017) 6(3):267-70. doi: $10.1556 / 2006.5 .2016 .088$

17. Wood RT. Problems with the concept of video game "addiction": some case study examples. Int J Ment Health Addict (2008) 6(2):169-78. doi: 10.1007/ s11469-007-9118-0

18. Potenza MN. Should addictive disorders include non-substance-related conditions? Addiction (2006) 101(s1):142-51. doi: 10.1111/j.1360-0443. 2006.01591.x

19. King DL, Herd MCE, Delfabbro PH. Tolerance in internet gaming disorder: a need for increasing gaming time or something else? J Behav Addict (2017) 6(4):525-33. doi: 10.1556/2006.6.2017.072

20. van Rooij AJ, Ferguson CJ, Colder Carras M, Kardefelt-Winther D, Shi J, Aarseth E, et al. A weak scientific basis for gaming disorder: let us err on the side of caution. J Behav Addict (2018) 7(1):1-9. doi: 10.31234/osf.io/kc7r9

21. Rumpf HJ, Achab S, Billieux J, Bowden-Jones H, Carragher N, Demetrovics $\mathrm{Z}$, et al. Including gaming disorder in the ICD-11: the need to do so from a clinical and public health perspective: commentary on: a weak scientific basis for gaming disorder: let us err on the side of caution (van Rooij et al., 2018). J Behav Addict (2018) 7(3):556-61. doi: 10.1556/2006.7.2018.59 
22. Potenza MN. Do gaming disorder and hazardous gaming belong in ICD11 ? Considerations regarding the death of a hospitalized patient that was reported to have occurred while a care provider was gaming. J Behav Addict (2018) 7(2):206-7. doi: 10.1556/2006.7.2018.42

23. Robinson SM, Adinoff B. The classification of substance use disorders: historical, contextual, and conceptual considerations. Behav Sci (2016) 6(3):18. doi: 10.3390/bs6030018

24. van Heugten-van der Kloet D, van Heugten T. The classification of psychiatric disorders according to DSM-5 deserves an internationally standardized psychological test battery on symptom level. Front Psychol (2015) 6:1108. doi: 10.3389/fpsyg.2015.01108

25. Weinstein AM. An update overview on brain imaging studies of internet gaming disorder. Front Psychiatry (2017) 8:185. doi: 10.3389/fpsyt.2017.00185

26. Potenza MN. How central is dopamine to pathological gambling or gambling disorder? Front Behav Neurosci (2013) 7:206. doi: 10.3389/fnbeh.2013.00206

27. Potenza MN. Searching for replicable dopamine-related findings in gambling disorder. Biol Psychiatry (2018) 83:984-6. doi: 10.1016/j.biopsych.2018.04. 011

28. Nutt DJ, Lingford-Hughes A, Erritzoe D, Stokes PR. The dopamine theory of addiction: 40 years of highs and lows. Nat Rev Neurosci (2015) 16(5):305. doi: 10.1038/nrn3939

29. Kim SH, Baik SH, Park CS, Kim SJ, Choi SW, Kim SE. Reduced striatal dopamine D2 receptors in people with Internet addiction. Neuroreport (2011) 22(8):407-11. doi: 10.1097/WNR.0b013e328346e16e

30. Hou H, Jia S, Hu S, Fan R, Sun W, Sun T, et al. Reduced striatal dopamine transporters in people with Internet addiction disorder. Biomed Res Int (2012) 2012(854524):5 p. doi: 10.1155/2012/854524

31. Tian M, Chen Q, Zhang Y, Du F, Hou H, Chao F, et al. PET imaging reveals brain functional changes in Internet gaming disorder. Eur J Nucl Med Mol Imaging (2014) 41(7):1388-97. doi: 10.1007/s00259-014-2708-8

32. Han DH, Lee YS, Yang KC, Kim EY, Lyoo IK, Renshaw PF. Dopamine genes and reward dependence in adolescents with excessive internet video game play. J Addict Med (2007) 1(3):133-8. doi: 10.1097/ADM.0b013e31811f465f

33. Yang BZ, Kranzler HR, Zhao H, Gruen JR, Luo X, Gelernter J. Association of haplotypic variants in DRD2, ANKK1, TTC12 and NCAM1 to alcohol dependence in independent case-control and family samples. Hum $\mathrm{Mol}$ Genet (2007) 16(23):2844-53. doi: 10.1093/hmg/ddm240

34. Dick DM, Wang JC, Plunkett J, Aliev F, Hinrichs A, Bertelsen S, et al. Familybased association analyses of alcohol dependence phenotypes across DRD2 and neighboring gene ANKK1. Alcohol Clin Exp Res (2007) 31(10):1645-53. doi: 10.1111/j.1530-0277.2007.00470.x

35. Han DH, Hwang JW, Renshaw PF. Bupropion sustained release treatment decreases craving for video games and cue-induced brain activity in patients with internet video game addiction. Exp Clin Psychopharmacol (2010) 18(4):297. doi: 10.1037/a0020023

36. Han DH, Lee YS, Shi X, Renshaw PF. Proton magnetic resonance spectroscopy (MRS) in on-line game addiction. J Psychiatr Res (2014) 58:63-68. doi: 10.1016/j.jpsychires.2014.07.007

37. Liu L, Yip SW, Zhang JT, Wang LJ, Shen ZJ, Liu B, et al. Activation of the ventral and dorsal striatum during cue reactivity in internet gaming disorder. Addict Biol (2017) 22(3):791-801. doi: 10.1111/adb.12338

38. Dong G, Zheng H, Liu X, Wang Y, Du X, Potenza MN. Gender-related differences in cue-elicited cravings in Internet gaming disorder: the effects of deprivation. J Behav Addict (2018) 7(4):953-64. doi: 10.1556/2006.7.2018.118

39. Dong G, Wang Z, Wang Y, Du X, Potenza MN. Gender-related functional connectivity and craving during gaming and immediate forced abstinence: implications for development and progression of internet gaming disorder. Prog Neuropsychopharmacol Biol Psychiatry (2019) 88:1-10. doi: 10.1016/j. pnpbp.2018.04.009

40. Zhang JT, Ma SS, Yip SW, Wang LJ, Chen C, Yan CG, et al. Decreased functional connectivity between ventral tegmental area and nucleus accumbens in internet gaming disorder: evidence from resting state functional magnetic resonance imaging. Behav Brain Funct (2015) 11(1):37. doi: 10.1186/ s12993-015-0082-8

41. Zhang Y, Mei W, Zhang JX, Wu Q, Zhang W. Decreased functional connectivity of insula-based network in young adults with internet gaming disorder. Exp Brain Res (2016) 234(9):2553-60. doi: 10.1007/ s00221-016-4659-8
42. Zhang J-T, Yao Y-W, Potenza MN, Xia C-C, Lan J, Liu L, et al. Effects of craving behavioral intervention on neural substrates of cue-induced craving in internet gaming disorder. Neuroimage Clin (2016) 12:591-9. doi: 10.1016/j.nicl.2016.09.004

43. Zhang J-T, Yao Y-W, Potenza MN, Xia C-C, Liu L, Lan J, et al. Altered restingstate neural activity and changes following a craving behavioral intervention for internet gaming disorder. Sci Rep (2016) 6:28109. doi: 10.1038/srep28109

44. Dong G, Potenza MN. A cognitive-behavioral model of internet gaming disorder: theoretical underpinnings and clinical implications. J Psychiatr Res (2014) 58:7-11. doi: 10.1016/j.jpsychires.2014.07.005

45. Brand $\mathrm{M}$, Young $\mathrm{K}$, Laier $\mathrm{C}$, Wölfling $\mathrm{K}$, Potenza MN. Integrating psychological and neurobiological considerations regarding the development and maintenance of specific Internet-use disorders: an Interaction of PersonAffect-Cognition-Execution (I-PACE) model. Neurosci Biobehav Rev (2016) 71:252-66. doi: 10.1016/j.neubiorev.2016.08.033

46. Dong G, Lin X, Potenza MN. Decreased functional connectivity in an executive control network is related to impaired executive function in internet gaming disorder. Prog Neuropsychopharmacol Biol Psychiatry (2015) 57:76-85. doi: 10.1016/j.pnpbp.2014.10.012

47. Dong G, Li H, Wang L, Potenza MN. Cognitive control and reward/loss processing in Internet gaming disorder: results from a comparison with recreational internet game-users. Eur Psychiatry (2017) 44:30-8. doi: 10.1016/j.eurpsy.2017.03.004

48. Liu L, Xue G, Potenza MN, Zhang JT, Yao YW, Xia CC, et al. Dissociable neural processes during risky decision-making in individuals with internet-gaming disorder. Neuroimage Clin (2017) 14:741-9. doi: 10.1016/j.nicl.2017.03.010

49. Lin X, Zhou H, Dong G, Du X. Impaired risk evaluation in people with internet gaming disorder: fMRI evidence from a probability discounting task. Prog Neuropsychopharmacol Biol Psychiatry (2015) 56:142-8. doi: 10.1016/j.pnpbp.2014.08.016

50. Yip SW, Gross JJ, Chawla M, Ma SS, Shi XH, Liu L, et al. Is neural processing of negative stimuli altered in addiction independent of drug effects? Findings from drug-naïve youth with internet gaming disorder. Neuropsychopharmacology (2018) 43(6):1364-72. doi: 10.1038/npp.2017.283

51. Yao Y, Liu L, Ma SS, Shi XH, Zhou N, Zhang JT, et al. Functional and structural brain alterations in internet gaming disorder: a systematic review and meta-analysis. Neurosci Biobehav Rev (2017) 83:313-24. doi: 10.1016/j. neubiorev.2017.10.029

52. Worhunsky PD, Malison RT, Rogers RD, Potenza MN. Altered neural correlates of reward and loss processing during simulated slot-machine fMRI in pathological gambling and cocaine dependence. Drug Alcohol Depend (2014) 145:77-86. doi: 10.1016/j.drugalcdep.2014.09.013

53. Kober H, Lacadie C, Wexler BE, Malison RT, Sinha R, Potenza MN. Brain activity during cocaine craving and gambling urges: an fMRI study. Neuropsychopharmacology (2016) 41(2):628-37. doi: 10.1038/npp.2015.193

54. Worhunsky PD, Malison RT, Potenza MN, Rogers RD. Alterations in functional brain networks associated with loss-chasing in gambling disorder and cocaine-use disorder. Drug Alcohol Depend (2017) 178:363-71. doi: 10.1016/j.drugalcdep.2017.05.025

55. Fauth-Bühler M, Mann K. Neurobiological correlates of internet gaming disorder: similarities to pathological gambling. Addict Behav (2017) 64:34956. doi: 10.1016/j.addbeh.2015.11.004

56. Ko CH, Liu GC, Yen JY, Yen CF, Chen CS, Lin WC. The brain activations for both cue-induced gaming urge and smoking craving among subjects comorbid with internet gaming addiction and nicotine dependence. J Psychiatr Res (2013) 47(4):486-93. doi: 10.1016/j.jpsychires.2012.11.008

57. Kim H, Kim YK, Gwak AR, Lim JA, Lee JY, Jung HY, et al. Resting-state regional homogeneity as a biological marker for patients with Internet gaming disorder: a comparison with patients with alcohol use disorder and healthy controls. Prog Neuropsychopharmacol Biol Psychiatry (2015) 60:10411. doi: 10.1016/j.pnpbp.2015.02.004

58. Han JW, Han DH, Bolo N, Kim B, Kim BN, Renshaw PF. Differences in functional connectivity between alcohol dependence and internet gaming disorder. Addict Behav (2015) 41:12-19. doi: 10.1016/j.addbeh.2014.09.006

59. Yip SW, Worhsunky PD, Xu J, Constable RT, Malison RT, Carroll KM, et al. Gray-matter relationships to diagnostic and transdiagnostic features of drug and behavioral addictions. Addict Biol (2018) 23(1):394-402. doi: 10.1111/ adb. 12492 
60. Wang Z, Wu L, Yuan K, Hu Y, Zheng H, Du X, et al. Cortical thickness and volume abnormalities in internet gaming disorder: evidence from comparison of recreational internet game users. Eur J Neurosci 48:1654-66. doi: 10.1111/ejn.13987

61. Dong G, Liu X, Wang M, Liang Q, Du X, Potenza MN. Cue-elicited-cravingrelated lentiform activation during gaming deprivation relates to emergence of internet gaming disorder. Addict Biol (2019) 1-9. doi: 10.1111/adb.12713

62. Dong G, Wu L, Wang Y, Du X, Potenza MN. Diffusion-weighted MRI measures suggest better white-matter integrity in Internet gaming disorder: evidence from the comparison with recreational internet game users. Addict Behav (2018) 81:32-8. doi: 10.1016/j.addbeh.2018.01.030

63. Han DH, Lyoo IK, Renshaw PF. Differential regional gray matter volumes in patients with on-line game addiction and professional gamers. J Psychiatr Res (2012) 46(4):507-15. doi: 10.1016/j.jpsychires.2012.01.004

64. Yilmaz Soylu M, Bruning RH. Exploring self-regulation of more or lessexpert college-age video game players: a sequential explanatory design. Front Psychol (2016) 7(1441). doi: 10.3389/fpsyg.2016.01441

65. Koob GF. The neurobiology of addiction: a neuroadaptational view relevant for diagnosis. Addiction (2006) 101(s1):23-30. doi: 10.1111/j.1360-0443. 2006.01586.x

66. Fineberg NA, Potenza MN, Chamberlain SR, Berlin H, Menzies L, Bechara A, et al. Probing compulsive and impulsive behaviors, from animal models to endophenotypes; a narrative review. Neuropsychopharmacology (2010) 35:591-604. doi: 10.1038/npp.2009.185

67. Fineberg NA, Chamberlain SR, Goudriaan AE, Stein DJ, Vandershuren L, Gillan CM, et al. New developments in human neurocognition: clinical, genetic and brain imaging correlates of impulsivity and compulsivity. CNS Spectr (2014) 19:69-89. doi: 10.1017/S1092852913000801

68. Yip SW, Potenza MN. Application of research domain criteria to childhood and adolescent impulsive and addictive disorders: implications for treatment. Clin Psychol Rev (2018) 64:41-56. doi: 10.1016/j.cpr.2016.11.003

69. Su W, Potenza MN, Zhang Z, Hu X, Gao L, Wang Y. Do individuals with problematic and non-problematic internet game use differ in cooperative behaviors? Evidence from the prisoner's dilemma and chicken game. Comput Human Behav (2018) 87:363-70. doi: 10.1016/j.chb.2018.05.040

70. Su W, Király O, Demetrovics Z, Potenza MN. Gender moderates the partial mediation of impulsivity in the relationship between psychiatric distress and problematic online gaming. J Med Internet Res Ment Health (2019) 6(3):e10784. doi: 10.2196/10784

71. Leménager T, Dieter J, Hill H, Koopmann A, Reinhard I, Sell M, et al. Neurobiological correlates of physical self-concept and self-identification with avatars in addicted players of Massively Multiplayer Online RolePlaying Games (MMORPGs). Addict Behav (2014) 39(12):1789-97. doi: 10.1016/j.addbeh.2014.07.017

72. Dieter J, Hill H, Sell M, Reinhard I, Vollstädt-Klein S, Kiefer F, et al. Avatar's neurobiological traces in the self-concept of massively multiplayer online role-playing game (MMORPG) addicts. Behav Neurosci (2015) 129(1):8. doi: $10.1037 /$ bne0000025

73. Kim MK, Jung YH, Kyeong S, Shin YB, Kim E, Kim JJ. Neural correlates of distorted self-concept in individuals with internet gaming disorder: a functional MRI study. Front Psychiatry (2018) 9:330. doi: 10.3389/fpsyt. 2018.00330

74. Fineberg NA, Demetrovics Z, Stein DJ, Corazza O, Ioannidis K, Menchon J, et al. Manifesto for a European Research Network into problematic usage of the internet. Eur Neuropsychopharmacol (2018) 28(11):1232-46. doi: 10.1016/j.euroneuro.2018.08.004
75. Castro-Calvo J, Ballester-Arnal R, Potenza MN, King DL, Billieux J. Does "forced abstinence" from gaming lead to pornography use? Insight from an April 2018 crash of Fortnite's servers. J Behav Addict (2018) 7(3):501-2. doi: 10.1556/2006.7.2018.78

76. Potenza MN, Higuchi S, Brand M. Call for research into a wider range of behavioural addictions. Nature (2018) 555:30. doi: 10.1038/d41586-018-02568-Z

77. Yau MYH, Potenza MN. Gambling disorder and other behavioral addictions: recognition and treatment. Harv Rev Psychiatry (2015) 23(2):134. doi: 10.1097/HRP.0000000000000051

78. Na E, Choi I, Lee TH, Lee H, Rho MJ, Cho H, et al. The influence of game genre on Internet gaming disorder. J Behav Addict (2017) 6(2):248-55. doi: 10.1556/2006.6.2017.033

79. Király O, Böthe B, Ramos-Diaz J, Rahimi-Movaghar A, Lukavska K, Hrabec $\mathrm{O}$, et al. Ten-Item Internet Gaming Disorder Test (IGDT-10): cross-cultural validation across seven language-based samples. Psychol Addict Behav (2019) 33(1):91-103. doi: 10.1037/adb0000433

80. Slutske WS. Natural recovery and treatment-seeking in pathological gambling: results of two U.S. national surveys. Am J Psychiatry (2006) 163(2):297-302. doi: 10.1176/appi.ajp.163.2.297

81. Lau JTF, Wu AMS, Gross DL, Cheng KM, Lau MMG. Is internet addiction transitory or persistent? Incidence and prospective predictors of remission of internet addiction among Chinese secondary school students. Addict Behav (2017) 74:55-62. doi: 10.1016/j.addbeh.2017.05.034

82. Han DH, Yoo M, Renshaw PF, Petry NM. A cohort study of patients seeking internet gaming disorder treatment. J Behav Addict (2018) 7(4):930-8. doi: 10.1556/2006.7.2018.102

83. Bullock SA, Potenza MN. Pathological gambling: neuropsychopharmacology and treatment. Curr Psychopharmacol (2012) 1:67-85. doi: 10.2174/221155 7911201010067

84. King DL, Potenza MN. Not playing around: gaming disorder in the ICD-11. J Adolesc Health (2019) 64(1):5-7. doi: 10.1016/j.jadohealth.2018.10.010

85. King DL, Gaming industry response consortium. Comment on the global gaming industry's opposition to ICD-11 gaming disorder: a corporate strategy to disregard evidence and deflect social responsibility? Addiction (2018) 113(11):2145-6. doi: 10.1111/add.14388

86. Billieux J, King DL, Higuchi S, Achab S, Bowden-Jones H, Hao W, et al. Functional impairment matters in the screening and diagnosis of gaming disorder. J Behav Addict (2017) 6(3):285-9. doi: 10.1556/2006.6.2017.036

Conflict of Interest Statement: AV and MP have no conflicts of interest with respect to the contents of the manuscript. MP declares the following. M.N.P. has consulted for and advised Shire, INSYS, RiverMend Health, Addiction Policy Forum, Game Day Data, the National Council on Problem Gambling, Opiant/Lightlake Therapeutics, and Jazz Pharmaceuticals; has received unrestricted research support from Mohegan Sun Casino and grant support from the National Center for Responsible Gaming; and has consulted for and advised legal and gambling entities on issues related to addictions and impulse control disorders. He has also participated in World Health Organization meetings relating to IGD and GD. The remaining author declares that the research was conducted in the absence of any commercial or financial relationships that could be construed as a potential conflict of interest.

Copyright (C) 2019 Vaccaro and Potenza. This is an open-access article distributed under the terms of the Creative Commons Attribution License (CC BY). The use, distribution or reproduction in other forums is permitted, provided the original author(s) and the copyright owner(s) are credited and that the original publication in this journal is cited, in accordance with accepted academic practice. No use, distribution or reproduction is permitted which does not comply with these terms. 